\title{
Interaction Between Values of Anthropometric Body and Static Balance Related to the Characeristics of the Three Plastic Fitness Equipment
}

\author{
DANA BADAU1,2, ADELA BADAU ${ }^{3} *$, ADRIANA CLIPA ${ }^{4}$ \\ ${ }^{1}$ University of Medicine, Pharmacy, Sciences and Technology of Targu Mures, Department of Human Movement Sciences, 38 \\ Gh. Marinescu Str., 540139, Tirgu Mures, Romania \\ ${ }^{2}$ Transilvania University of Brasov, Interdisciplinary Doctoral School, 29 Eroilor Str., 500036, Brasov, Romania \\ ${ }^{3}$ University of Medicine, Pharmacy, Sciences and Technology of Targu Mures, Department of Physical Education, 38 Gh. \\ Marinescu St., 540139, Tirgu Mures, Romania \\ ${ }^{4}$ Ovidius University of Constanta, Department of Medical Clinic, 1 Aleea Universitatii Str., 900470, Constanta, Romania
}

\begin{abstract}
The study aimed to highlight how unipodal stable equilibrium values are depending on the technical characteristics of plastic fitness equipment in relation to some anthropometric indices in order to optimize the physical potential. The best results recorded for the static balance test for both legs was on the Stability Disc, followed by Balance Board executions, and the weakest results were obtained on the Bosu Ball. The executions on the right leg were superior to executions on the left leg.
\end{abstract}

Keywords: fitness, plastic equipment, Bosu Ball, Stability Disc, Balance Board

The trend in physical activities, aimed to improve physical fitness, proprioception, balance and postural stability, is the usage of unstable equipment made of plastic. The plastic equipment designed for improving and rehabilitating balance, allow for three-dimensional movements and facilitate body adaptation to balance movements $[1,2]$.

The manufacture and use of plastic equipmentholds an impressive evolution and development [3,4], contributing to optimizing health, functional and motor rehabilitation, and improving the human motor potential [5]. The use of plastic sports equipment with different properties and technical specifications may lead to improvement of proprioception and, implicitly, of balance in relation to anthropometric characteristics $[6,7]$.

Plastic sports equipment is characterized by a number of technical aspects such as power, density, elasticity, ductility and wear resistance. The use of interdisciplinary knowledge in materials science, mechanical engineering, chemistry, physics, anatomy, physiology and biomechanics are indispensable to the design and manufacture of plastic equipment for the education of balance in sanogenous or sporting environments [9-11].

Balance is a multidimensional concept that targets the human postural stabilization capacity by controlling the body mass center with respect to the supporting surface being influenced by the level of: physical training, age, anthropometric parameters and on the functionality of analyzers etc. [12-14].

The Bosu Ball is made of plastic with semi-rounded ABS (anti-burst system) technology, with a diameter of $65 \mathrm{~cm}$, weight $4.54 \mathrm{~kg}$, maximum weight supported $300 \mathrm{~kg}$, with the following technical characteristics: increased resistance and adhesion, anti-burst, textured and non-slip surface. Bosu ball is used in: fitness, aerobic gymnastics, medical gymnastics for muscle toning, functional and motor recovery or the education of the proprioceptive capacity, etc. $[15,16]$.

The Stability Disc, also called Dyna Disc, is a $33 \mathrm{~cm}$ diameter air-filled platform, made of PVC with height of $9.5 \mathrm{~cm}$, and maximum load supported is $100 \mathrm{~kg}$, with the following features: enhanced resistance and adhesion, anti-explosion, anti-burst, surface textured and anti-slip.
The use of the Stability Disc aims to: educate balance and proprioception, muscle toning, functional and motor recovery, postural correction etc. [16-18].

Balance board or Wobble Board is made of hard plastic with a non-slip surface, $42 \mathrm{~cm}$ in diameter, with $8 \mathrm{~cm}$ adjustable height, and a capacity of $100 \mathrm{~kg}$ maximum load, used to improve and re-equalize the balance, muscle toning, and the motor rehabilitation of the ankle [20-22].

A series of previous studies using the same plastic sports equipment, similar to those included in our study, emphasized health optimization, neuromotor and functional rehabilitation $[23,24]$ and physical performances $[25,19]$ without however targeting to correlate the data according to the properties and technical characteristics of the sports equipment.

The novelty of our study consists in the use of three types of sports equipment made of plastics with different characteristics and properties designed to improve the physical capacity and especially the static balance, according to the anthropometric indices of the subjects.

The aim of the study was to highlighthow unipodal stable equilibrium values depend on the technical characteristics of plastic sports equipment in relation to some anthropometric indices in order to optimize the physical potential.

We believe that the characteristics and properties of sports equipment in plastic materials influence the motor performance of physical and sports practitioners.

\section{Experimental part}

\section{Materials and methods}

The study was conducted between April and May 2018 on a sample of 60 volunteer students from the Physical and Sports Education program at the University of Medicine and Pharmacy in Tirgu Mures. The sample was formed only by male students, with average age $X 21.763$ years, SD 1.213; average height $X 179.583$ m, SD 6.090; average weight $X 77.230 \mathrm{~kg}, \mathrm{SD} 9.887$; average leg length of the dominant leg $X 26.501 \mathrm{~cm}$, SD 1.421; median width of dominant leg X $10.056 \mathrm{~cm}$, SD 1.374; all subjects have the right foot dominant. The tests were conducted on the basis of ethical principles specific to human subjects in accordance with the 2008 Helsinki Declaration.

* email: adela.badau@umftgm.ro; Phone: +40723261514 
Using the electronic throttle scale, the height $(\mathrm{H})$ in $\mathrm{cm}$ and the weight (W) in kg for each subject were measured. To measure the foot paw $(\mathrm{cm})$, the plantar footprint was used for the measurement of the foot length (FPL) a gauge was used to establish the distance from the heel to the longest toe and the footplate width (FPW) was determined by the distance between the finger mounts of the big finger and the base of the little finger.

Static balance testing was performed with the Flamingo test, alternately performed on the dominant and nondominant leg. The Flamingo test consists of keeping the balance on one leg with the other bent and supported on the inner knee of the support leg; the arms are bent with their hands on the hips, the exercise is executed barefoot. The timer is started when the subject is in the correct position. The stopwatch is switched off if any of the following situations: the hand (s) is moving away from the hips; the support leg moves sharply in any direction; the non-support foot loses contact with the knee. Time has been registered as long as subjects have kepttheir balance until they unbalanced.

The order of tests of the stable balance according to the equipment used was the following: Bosu Ball, Stability Disc and Balance Board, the first test was on the dominant leg and the second on the non-dominant. The break between the tests on the three sports equipment was 30 min.

The results of the research were processed in SPSS 20., calculating the statistical indicators: arithmetic mean $(X)$, standard deviation (SD), one sample Student' test; Multivariate Test by ANOVA for: partial eta-squared ( $\eta \mathrm{p} 2)$, noncent. Parameter, observed power. The test of homogeneity of variances revealed: sums of squares (df1, df1), F values, and significance levels. The meaning of effect size through partial eta-squared ( $\eta$ p2) [26] were: small 0.2 , medium 0.5 and large 0.8 . The significance threshold considered relevant for the study was $p<0.05$, $95 \%$ confidence interval $(\mathrm{Cl})$.

\section{Results and discussions}

The differences between the right leg and left leg executions for the Flamingo test were statistically significant: Bosu Ball X 5.116 S, SD 6.012, Stability Disc X 6.632 sec., SD 14.329 and Balance Board X 7.497 sec., SD 11.751 (table 1).

The recorded results for the dominant leg regarding the static equilibrium on the three types of plastic equipment used were statistically significant as follows: between Stability Disc and Bosu Ball X 14.440 sec., SD 15.838, between Balance Board and Bosu Ball X 12.030 sec., SD 12.676, and between Stability Disc and Balance Board X 2.410 sec., SD 17.147 (table 1).

The non-dominant (left) leg executions, using the Flamingo test revealed the following results on the three types of equipment used in the study: between Stability Disc and Bosu Ball X 12.923 sec, SD 16.665, between Balance Board and Bosu Ball X $9.648 \mathrm{sec}$, SD 10.899, and between Stability Disc and Balance Board X $3.275 \mathrm{sec}$, SD 14.174, the results being statistically significant for $p 0.05$ (table 1).

The probability of correctrejection of the null hypothesis is evidenced by the observed power (table 2).

The interaction between the anthropometric parameters and the equilibrium capacity on the three types of plastic used in the study revealed the following effect size: for $\eta p 2<0.20$ small effect between the foot paw width and the left leg executions on the Stability Disc; for $\eta p 2>0.80$ large effect size between weight and left foot executions on Bosu Ball, Balance Board and Stability Disc: between weight and right foot balance on Stability Disc and between height and rightfootbalance on Stability Disc; all other interactions were between $\eta \mathrm{p} 20.5$ and 0.80 indicating an average effect size (table 2).

For Bosu Ball, the main effects of the interaction between height and static equilibrium on the right leg $\mathrm{F}$ $(20.39)=3.563, p=.000$ and the left leg $F(20.39)=$

Table I

DESCRIPTIVE STATISTICS OF THE RESULTS IN COORDONANCE WITH THE STATIC BALANCE ON THREE DIFFERENT TYPES OF EQUILIBRIUM EQUIPMENT IN ACCORDANCE WITH THE DOMINANT AND NON-DOMINANT FOOT

\begin{tabular}{|c|c|c|c|c|c|c|c|}
\hline Tests & Leg & Mean (sec.) & SD & $\mathrm{t}$ & p & $\mathrm{t}$ & p \\
\hline Bosu ball & $\begin{array}{l}\text { Right } \\
\text { Left }\end{array}$ & $\begin{array}{l}18.335 \\
13.219\end{array}$ & $\begin{array}{r}7.081 \\
-3.206\end{array}$ & $\begin{array}{r}20.055 \\
-31.933\end{array}$ & $\begin{array}{l}.000 \\
.000\end{array}$ & 6.591 & .000 \\
\hline $\begin{array}{l}\text { Stability disc } \\
\text { (Dyna Disc) }\end{array}$ & $\begin{array}{l}\text { Right } \\
\text { Left }\end{array}$ & $\begin{array}{r}32.775 \\
-26.142 \\
\end{array}$ & $\begin{array}{r}15.922 \\
-16.242\end{array}$ & $\begin{array}{r}15.945 \\
12.468\end{array}$ & $\begin{array}{l}.000 \\
.000\end{array}$ & 3.585 & .001 \\
\hline $\begin{array}{l}\text { Balance board } \\
\text { (Wobble Board) }\end{array}$ & $\begin{array}{l}\text { Right } \\
\text { Left }\end{array}$ & $\begin{array}{r}30.365 \\
22.867\end{array}$ & $\begin{array}{l}11.212 \\
10.035\end{array}$ & $\begin{array}{l}20.978 \\
17.651\end{array}$ & $\begin{array}{l}.000 \\
.000\end{array}$ & 4.942 & .000 \\
\hline
\end{tabular}

\begin{tabular}{|c|c|c|c|c|c|c|}
\hline Equipment & & & $\mathrm{H}$ & W & FPL & FLW \\
\hline \multirow[t]{6}{*}{ Bosu ball } & Right leg & $\eta_{p}{ }^{2}$ & .452 & .559 & .330 & .206 \\
\hline & & Noncent. Parameter & 32.150 & 43.080 & 23.111 & 12.982 \\
\hline & & Observed Power & .841 & .887 & .838 & .617 \\
\hline & Left leg & $\eta_{p^{2}}$ & .446 & .605 & .276 & 233 \\
\hline & & Noncent. Parameter & 31.452 & 51.999 & 17.898 & 15.187 \\
\hline & & Observed Power & .830 & 948 & .707 & .701 \\
\hline \multirow{6}{*}{$\begin{array}{l}\text { Stability disc } \\
\text { (Dyna disc) }\end{array}$} & Right leg & $n_{p}^{2}$ & .614 & .539 & .253 & .273 \\
\hline & & Noncent. Parameter & 23.853 & 39.673 & 15.918 & 18.814 \\
\hline & & Observed Power & 996 & .852 & .643 & .811 \\
\hline & Left leg & $\mathrm{np}^{2}$ & .347 & .571 & .242 & .130 \\
\hline & & Noncent. Parameter & 61.915 & 45.285 & 15.023 & 7.498 \\
\hline & & Observed Power & .601 & 906 & .611 & .362 \\
\hline \multirow{6}{*}{$\begin{array}{l}\text { Balance board } \\
\text { (Wobble } \\
\text { Board) }\end{array}$} & Right leg & $\eta_{p}^{2}$ & 347 & .401 & .276 & .159 \\
\hline & & Noncent. Parameter & 20.726 & 22.785 & 17.877 & 9.427 \\
\hline & & Observed Power & .601 & .547 & .707 & .456 \\
\hline & Left leg & $\eta_{p}^{2}$ & .385 & .731 & .336 & .207 \\
\hline & & Noncent. Parameter & 24.420 & 92.524 & 23.795 & 13.034 \\
\hline & & Observed Power & .695 & 999 & .851 & .619 \\
\hline
\end{tabular}

Table 2

DESCRIPTIV STATISTIC OF MULTIVARIATE IN COORDONANCE WITH THE STATIC BALANCE ON THREE DIFFERENT TYPES OF EQUILIBRIUM EQUIPMENT IN ACCORDANCE WITH THE DOMINANT AND NONDOMINANT FOOT 
$2.779, p=.003$ were statistically significant. The effect between the static height and static equilibrium on the Stability Disc was statistically significant for both legs, so for the right leg $F(20.39)=4.258, p=.000$ and for the left $F(20.39)=7.822, p=.000$. The interaction between height and balance on the Balance Board revealed a statistically significant effect for both the right leg $F(20,39)=2.198, p$ $=.017$, and for the left leg $F(20.39)=3.140, p=.001$.

The effect of the interaction between the weight and the stable balance on the right leg and on the left leg depending on the equipment used was statistically significant, so for Bosu Ball on the right leg $\mathrm{F}(25,34)=$ $2.042, p=.027$, on the left leg $F(25.34)=2.579, p=.005$; for Stability Disk on right leg $\mathrm{F}(25.34)=2.021, p=.028$, on left leg $F(25.34)=4.266, p=.000$; for Balance Board on the right leg $F(25,34)=1,900, p=.041$, on the left leg $F$ $(25.34)=1.944, p=.001$.

For Bosu Ball, the effect of the interaction between foot length and static equilibrium were statistically significant for both legs, so for the right leg $F(12.47)=5.852, p=.000$ and the left leg $F(12.47)=2.089, p=.036$. The interaction betw een the leg's foot length and the static equilibrium on the Stability disc determined a statistically significant effect, so for the right leg $F(12,47)=2.054, p=.040$, but statistically insignificant for the left leg $F(12.47)=1.542$, $p=.143$. On the Balance board, the interaction between the length of the foot and the stable balance revealed an insignificant statistical effect for the right leg $\mathrm{F}(12.47)=$ $1.794, p=.077$, but statistically significant for the left leg $F$ $(12.47)=2.583, p=.010$.

The effect of the interaction between the foot width and the stable balance on the right leg and left leg depending on the equipment used were statistically significant for the Bosu Ball on the left leg $F(9.50)=2.223, p=.036$; for Balance Board on the right leg $F(9.50)=2.269, p=.032$ and on the left leg $F(9.50)=3.365, p=.003$. The study revealed a statistically insignificant effect between foot width and right leg equilibrium on Bosu Ball $F(9.50)=$ $1.119, p=.3673$ and Stability Disc test for right leg $F$ (12.47) $=1.420, p=.205$ and for the left leg $F(12.47)=2.011, p=$ .058 .

The findings of our study complete past and recent studies and challenge future approaches regarding the impact of plastic equipment in sports and medical rehabilitation.

The instability of a device depends on, or can be, manipulated by modifying the surface of the base of the holder, by altering the vertical and horizontal diameters of the device, by the design of the device, etc. [18].

\section{Conclusions}

The best recorded results for the static equilibrium test for both legs was on the Stability Disc, followed by executions on the Balance Board, and the weakest results were obtained on the Bosu Ball. The executions on the dominant (right) leg were superior to executions on the non-dominant (left) leg.

The anthropometric characteristics of the subjects in relation to the static equilibrium capacity mainly revealed a mean and wide effect size for the executions on the used plastics equipment, except for the interaction between foot paw width and the equilibrium capacity for which the magnitude of the effect was predominantly small.

The technical characteristics of the sporting equipment used to improve the balance, significantly influenced motric performance, the more elastic, the higher the diameter and the lower the base of the equipment, the more stable equilibrium-state performance is lower. Better stability can be achieved by using different postural positions, by using equipment with different technical characteristics and design, which requires a specific proprioceptive adaptation of the subjects, with efficient applicability in fitness, aerobic gymnastics and medical gymnastics.

\section{References}

1.PAHONIE, R.C., STEFAN, A., ADOCHIEI, I.R., COSTULEANU, CL., ANDRUSEAC, G.G., UNGUREANU, G., SARDARU, D.P., Mat.Plast., 54, no.2, 2017, p. 396-401;

2.BEHM, D., COLADO, J.C., Int J Sports Phys Ther, 7, 2012, p. 226-241; 3.DUDESCU, C., BOTEAN, A., HARDAU, M., Mat.Plast., 50, no. 1, 2013, p. 55- 59;

4.MARIES, R.E., MANOVICIU, I., BANDUR, G., RUSU, G. PODE, V., Mat. Plast., 44, no. 4, 2007, p. 289-293;

5.DUSA, F.S., BADAU, A., BADAU, D., TRAMBITAS, C., BRINZANIUC, K., Mat.Plast., 54, no. 4, 2017, p. 606-609;

6.LEE, C.L., CHU, I.H., LYU, B.J ., CHANG, W.D., CHANG, N.J ., J SAPORTS Sci., 2018, p. 1-8. doi: 10.1080/02640414.2018.1469848. [Epub ahead of print];

7.DOMINIQUEZ-NAVARRO, F., IGUAL-CAMACHI, C., SILVESTERMUNOZ, A., ROIG-CASASUS, S., BLASCO, J.M., Gait Posture, 62, 2018, p. 68-74. doi: 10.1016/j.gaitpost.2018.03.003.

8.CRISTIAN, T., POP, T.S., TRAMBITAS MIRON, A.D., DOROBANTU, D.C., BRINZANIUC, K., Rev.Chim.(Bucharest), 68, no. 2, 2017, p. 387389;

9.SUCIU, B.A., HALMACIU, VASILE BUD, V., COPOTOIU, C., FODOR, D.R.P., TRAMBITAS, C., VUNVULEA, V., MOLNAR, C., BRINZANIUC, K., Mat.Plast., 54, no. 3, 2017, p. 520-522;

10.KAUFMANN, J., Procedia Engineering, 112, 2015, p. 140 - 145;

11.SUBIS, A., MOURITZ, A., TROYNIKOV, O., Sports Technol.2, no. 3, 2009,p. 140-145;

12.CONDON, C., CREMIN, K., Physiother Res Int., 19, no. 1, 2014, p. 1-7;

13.BADAU, A., BADAU, D., SERBAN, C., TARCEA, M., RUS, V., J Pak Med Assoc., 68, no. 6, 2018, p. 882-887;

14.BADAU, D., BADAU, A., Sustainability, 10, no 6, 2018, p. 2106-2119: 15.*** https://patents.google.com/patent/US9700756B2/en;

16.ROMERO-FRANCO, N., MARTINEZ-LOPEZ, E.J., LOMAS-VEGA, R., HITA-CONTRERAS, F., OSUNA-PEREZ, M.C., MARTINEZ-AMAT, A., J Strength Cond Res., 27, no. 8, 2013, p. 2189-2197;

17.*** https://patents.google.com/patent/US8678985B2/en;

18.WAHL, M.J., BEHM, D.G., J Strength Cond Res., 22, no 4, 2008, p. 1360-1370;

19.WILLARDSON, J.M., J Strength Cond Res., 21, no. 3, 2007, p. 978$985 ;$

20.*** https://patents.google.com/patent/US6019712A/en

21.FUSCO, A., GIANCOTTI, G.F., FUCHS, P.X., WAGNER, H., VARALDA, C., CAPRANICA, L., CORTIS, C., J Strength Cond Res., 22, 2018, [Epub ahead of print];

22.SPARKES, R., BEHM, D.G., J Strength Cond Res., 24, no. 7, 2010, p. 1931-1941;

23.SIERRA-GUZMAN, R., J IMENEZ-DIAZ, F., RAMIREZ, C., ESTEBAN, P., ABIAN-VICEN, J., J. Athl Train., 53, no 4, 2018, p. 355-363;

24.BEHM, D.G., DRINKWATER, E.J., WILLARDSON, J.M., COWLEY, J.M., Appl Physiol Nutr Metab., 35, no. 1, 2010, p. 91-108;

25.CUG, M., DUNCAN, A., WIKSTROM, E., J. Athl Train., 51, no. 2, 2016, p. 101-110;

26.COHEN, J., Statistical Power Analysis for the Behavioral Sciences. New York, 1988, NY: Routledge Academic.

$\overline{\text { Manuscript received: } 29.09 .2018}$ 